\title{
Avaliação morfológica de pele e intestino de peixes expostos ao corante preto reativo 5
}

\author{
Morphological evaluation of fish skin and intestine exposed to reactive \\ black dye 5
}

\author{
Danúbia Querubim de Oliveira ${ }^{1}$, Daniel Bonoto Gonçalves², Hélio Batista dos \\ Santos ${ }^{1}$, Ralph Gruppi Thomé ${ }^{1}$
}

1- Laboratório de Processamento de Tecidos - Universidade Federal de São João Del Rei Campus Centro Oeste, Divinópolis, MG.

2- Processos Biotecnológicos e Purificação de Macromoléculas - Universidade Federal de São João Del Rei Campus Centro Oeste, Divinópolis, MG.

\section{Resumo}

A indústria têxtil desempenha papel importante na economia de muitos países e constitui um dos setores mais poluidores, especialmente, pela liberação de corantes têxteis de degradação recalcitrante nos corpos d'água. Azocorantes e seus produtos de degradação são mutagênicos e carcinogênicos, o que suscita avaliação do impacto desses poluentes em organismos do ecossistema. Em geral, peixes ficam expostos a xenobióticos por duas vias: ingestão ou contato direto. Assim, o presente trabalho teve como objetivo avaliar a morfologia da pele e intestino de peixes expostos ao corante Preto Reativo 5 por 30 dias. Para o ensaio toxicológico, 24 exemplares de Danio rerio foram divididos em quatro grupos: Controle (água da torneira); I (6 ppm); II (8 ppm) e III (10 ppm). Animais inteiros, foram submetidos às técnicas histológicas de rotina e Imunohistoquímica. Análises morfométricas foram realizadas no intestino delgado e na pele da região ventral. Não houve mortes durante a experimentação, os peixes mantiveram comportamento normal de natação e de alimentação. Após o experimento os tecidos do intestino e da pele de todos os animais apresentaram arquiteturas morfológicas sem modificações. Necrose, apoptose, formação de edema e perda de aderência também não foram observados. A pele apresentou aumento de células mucosas e de sua espessura $(\mathrm{p}<0,05)$. No intestino, observou-se aumento das vilosidades intestinais, de células em proliferação e células caliciformes $(\mathrm{p}<0,05)$. Através do presente trabalho foi possível confirmar a subletalidade das concentrações estudadas e foi demonstrando que a exposição ao corante PR5 causou alterações epiteliais na pele e no intestino.

Palavras-Chave: Zebrafish; Toxicologia; Impacto ambiental; Corantes. 


\section{Abstract}

The textile industry plays an important role in the economy of many countries and is one of the main polluting components, especially by the release of dyes from dry matter of recalcitrant degradation in water bodies. Azo dyes and their degradation products are mutagenic and carcinogenic, which raises the evaluation of the impact of these pollutants on organisms of the ecosystem. In general, fish are exposed to xenobiotics in two ways: ingestion or direct contact. Thus, we aimed to evaluate the morphology of the skin and intestine of fish exposed to Black Reactive Dye 5 for 30 days. For the toxicological test, 24 animals, Danio rerio, were divided into four groups: Control (tap water); I (6 ppm); II (8 ppm) and III (10 ppm). Whole animals were fixed and decalcified for histological and immunohistochemical techniques. Morphometric analyzes were performed in the small intestine and in the skin of the ventral region. There were no deaths during experimentation, the fish maintained normal swimming and feeding behavior. In all animals, the intestinal and skin tissues presented architecture without modifications, necrosis, apoptosis, edema, and loss of adhesion. The skin presented increased mucous cells and skin thickness $(\mathrm{p}<0.05)$. In the intestine, an increase in intestinal villi, proliferating cells and goblet cells was observed $(\mathrm{p}<0.05)$. Through the present work, it was possible to confirm the sublethal of the concentrations studied and it was demonstrated that this exposure to PR5 dye caused epithelial damages in the skin and intestine.

Keywords: Zebrafish; Toxicology; Environmental impact; Dyes

\section{Introdução}

As indústrias têxteis possuem significativa parcela na economia de diversos países, incluído o Brasil e, em especial, a região de Divinópolis, Minas Gerais ${ }^{1}$. A indústria de acabamento têxtil é um dos maiores poluidores entre os setores industriais, tanto em volume quanto em composição química do efluente liberado ${ }^{2}$. Os efluentes da indústria têxtil lançados nos cursos d'água podem ser nocivos às comunidades aquáticas e à saúde humana ${ }^{3}$. Esses efluentes podem conter altas concentrações de produtos químicos, muitos deles com potencias carcinogênicos e mutagênicos. Dentre esses compostos, destaca-se o corante Preto Reativo 5 (PR5), por ser um dos corantes reativos mais utilizados para acabamento têxtil, no mundo ${ }^{4,5,6}$

$\mathrm{O}$ ambiente aquático corresponde à grande parte do nosso meio ambiente e recursos e, portanto, a qualidade das águas está diretamente relacionada com a segurança da nossa saúde ${ }^{7}$. O efeito tóxico de corantes na fauna aquática pode ser um alerta precoce de potenciais danos para aos seres humanos. Tendo em vista essa relação do meio ambiente em comum e da similariedade genética os peixes se tornam ótimo modelo de experimentação ${ }^{8}$.

O Danio rerio, popularmente conhecido como zebrafish, peixe zebra ou paulistinha é um ciprinídeo originário da Ásia. Possui um pequeno porte, é de fácil manuseio, resistente e tem algumas características genéticas similares a dos mamíferos, tornando-se um dos mais importantes modelos de laboratório ${ }^{8,9}$. Em peixes, a absorção de poluentes ocorre por duas vias principais: trato digestivo (dieta) e pela superfície branquial, que são carreados no sangue até os órgãos alvo tais como: fígado, timo, baço e rim cranial ${ }^{10}$. Por representar uma das vias de entrada no corpo de poluentes o intestino foi escolhido, como órgão referência para o presente estudo. $\mathrm{O}$ intestino desempenha várias funções importantes no sistema digestório e consequentemente é um órgão chave para homeostase do organismo. Atualmente, além das vias principais de absorção de poluentes, a pele, maior órgão de vertebrados, tem despertado interesse em estudos toxicológicos e alterações observadas nesse órgão podem ser utilizadas como ferramenta de avaliação de danos. A pele é o órgão dos vertebrados que exerce a interface entre o organismo e o ambiente externo processando um conjunto enorme de informações tais como: pressão, temperatura e sinalizadores químicos ${ }^{11}$. Além disso, ao contrário de outros vertebrados, que possuem camadas protetoras de queratina, o tegumento dos peixes tem sua superfície com células epidérmicas vivas, expostas ao meio ambiente ${ }^{12}$. Assim, é possível que os tóxicos causem uma variação na espessura da multicamada epitelial, aumento de células club e mucosas bem como perda de junção entre as células.

Assim, dada a ausência na literatura da avaliação de possíveis danos histológicos causados pelo corante PR5 em peixes submetidos a um teste de toxicidade crônica, o presente estudo visa responder à principal pergunta: a exposição crônica do corante Preto Reativo 5, causa alterações em pele e em intestino de peixes? Nesse sentido, nós avaliamos parâmetros morfométricos e a quantificação do antígeno de proliferação celular (PCNA) nos órgãos de estudo. 


\section{Metodologia}

Para o ensaio toxicológico, 24 exemplares machos adultos de $D$. rerio, com comprimento médio de 3,35 $\pm 0,25 \mathrm{~cm}$ e peso médio de $0,363 \mathrm{~g} \pm 0,09 \mathrm{~g}$, obtidos comercialmente de criadores credenciados foram utilizados. Foi realizada aclimatação dos peixes por uma semana, e eles foram alimentados duas vezes ao dia com ração comercial e mantidos em aquários com água declorificada e aerada (oxigenação constante). O ensaio experimental foi realizado utilizando-se quatro aquários de três litros $(n=6)$ : Grupo Controle (água da torneira); Grupo I (6 ppm); Grupo II (8 ppm) e Grupo III (10 ppm). A concentração subletal do Corante Preto Reativo 5 foi baseada na literatura ${ }^{4}$. $\mathrm{O}$ experimento foi conduzido por 30 dias no sistema semiestático de exposição, com reposição da água e do corante (50 \%) a cada 7 dias. A temperatura do aquário seguiu a temperatura ambiente, com oxigenação constante e fotoperíodo 12/12 horas. Ao $30^{\circ}$ dia de experimentação, houve coleta de material biológico ( $n=6 /$ aquário). A eutanásia foi realizada por dose letal de anestésico (benzocaína $250 \mathrm{mg} / \mathrm{L}$ ) (Protocolo $\mathrm{n}^{\circ}$ 23/2012 Comissão de ética no uso de animais CEUA UFSJ). Com a intenção de minimizar o uso de animais, não foi realizado o cálculo da CL 50.

Após eutanásia, os animais inteiros foram fixados em líquido Bouin por $24 \mathrm{~h}$, descalcificados em ácido nítrico $10 \%$ por $48 \mathrm{~h}$, desidratados, diafanizados e incluídos em parafina. Os blocos de parafina contendo os espécimes foram submetidos a microtomia e obtidos cortes histológicos com $6 \mu \mathrm{m}$ de espessura que foram corados com Hematoxilina e Eosina (HE). Para identificação de glicoproteínas neutras, foi realizada a técnica histoquímica do Ácido Periódico + Reativo de Schifft (PAS).

Para identificação da proliferação celular, cortes histológicos com $5 \mu \mathrm{m}$ de espessura foram submetidos a técnica imuno-histoquímica utilizando anticorpo primário contra Antígeno Nuclear de Proliferação Celular (PCNA) na concentração de 1:200. A revelação foi feita com Kit LSAB 2 System HRP da Dako Cytomation (K 0675) contendo anticorpo secundário conjugado com biotina e estreptavidina conjugada com peroxidase. A identificação da peroxidase ligada ao anticorpo secundário foi feita com diaminobenzidina (DAB). Os cortes foram contra-corados com hematoxilina. $O$ controle negativo foi feito com cortes que não receberam os anticorpos primários, recebendo apenas o diluente.

Para as análises histológicas e morfométricas foram capturadas, sequencialmente, 10 imagens do intestino e 10 imagens das secções histológicas da pele na região ventral por animal, com objetiva de $40 \mathrm{x}$. As análises morfométricas foram realizadas por meio do analisador de imagens Motic Images Plus 2.0L.

Todos os testes estatísticos foram realizados utilizando o programa Graph Pad Instat versão 3.00 (Graph Pad Software, São Diego, CA, EUA). Foram consideradas somente as diferenças ao nível de $5 \%$ de significância $(\mathrm{p}<0,05)$.

\section{Resultados}

Não houve mortes durante a experimentação, e os peixes mantiveram comportamento normal de natação e de alimentação, indicando a subletalidade da concentração utilizada.

Microscopicamente o intestino do zebrafish é semelhante ao intestino de mamíferos e pode ser subdivido em 3 camadas histológicas: a mucosa, a submucosa e a muscular ${ }^{13,14}$. Na mucosa, o epitélio de revestimento observado foi do tipo prismático simples, constituído de células cilíndricas com borda estriada (microvilosidades) e também é observada a presença de células caliciformes, produtoras de muco. A submucosa apresentou tecido conjuntivo frouxo em continuidade com a lâmina própria da mucosa. A camada muscular foi constituída por células musculares lisas em disposição longitudinal. Não foram observadas alterações estruturais no intestino dos peixes expostos ao corante PR5, nem figuras de apoptose ou de necrose em nenhum dos grupos experimentais. (Figura 1). Por outro lado, CAMINHA, et al., usando nanotubos de carbono de parede única funcionalizados com polietilenoglicol (SWNT-PEG) verificaram mucosa e submucosa do intestino, com necrose, deposição de melanina e edema, além de infiltrados inflamatórios intensos principalmente por macrófagos na lâmina própria ${ }^{15}$.

Em todos os animais, o tecido epitelial de revestimento da pele apresentou-se estratificado, constituído por células epidérmicas, mucosas e de Club. (Figura 2). As células mucosas têm como função a produção de muco que nesse tecido, por exemplo, facilita o movimento na água e serve de proteção contra patógenos e lesões causadas por substâncias tóxicas ${ }^{16,17}$. As células de Club são classificadas como glândulas exócrinas unicelulares responsáveis pela produção de feromônios liberados em resposta a agentes tóxicos e estressantes ${ }^{18,19}$. Nos $D$. rerio expostos a 6,8 e $10 \mathrm{ppm}$, as células epiteliais apresentaram justaposição, sem perda de aderência célula-célula e célula-matriz, e com ausência de edemas, da mesma forma como nos peixes do grupo controle.

\section{Histoquímica do PAS}

Em todas as regiões analisadas do trato intestinal de zebrafish, as células caliciformes, a borda estriada e a membrana basal tiveram marcação positiva para PAS, demonstrando a presença de mucinas neutras (Figura 3). As mucinas neutras são conhecidas por suas funções de cooperação na digestão enzimática dos alimentos e por auxiliarem nas funções absortivas do intestino ${ }^{14}$. A membrana basal apresentou-se íntegra e não houve necrose e apoptose nas áreas estudadas. 

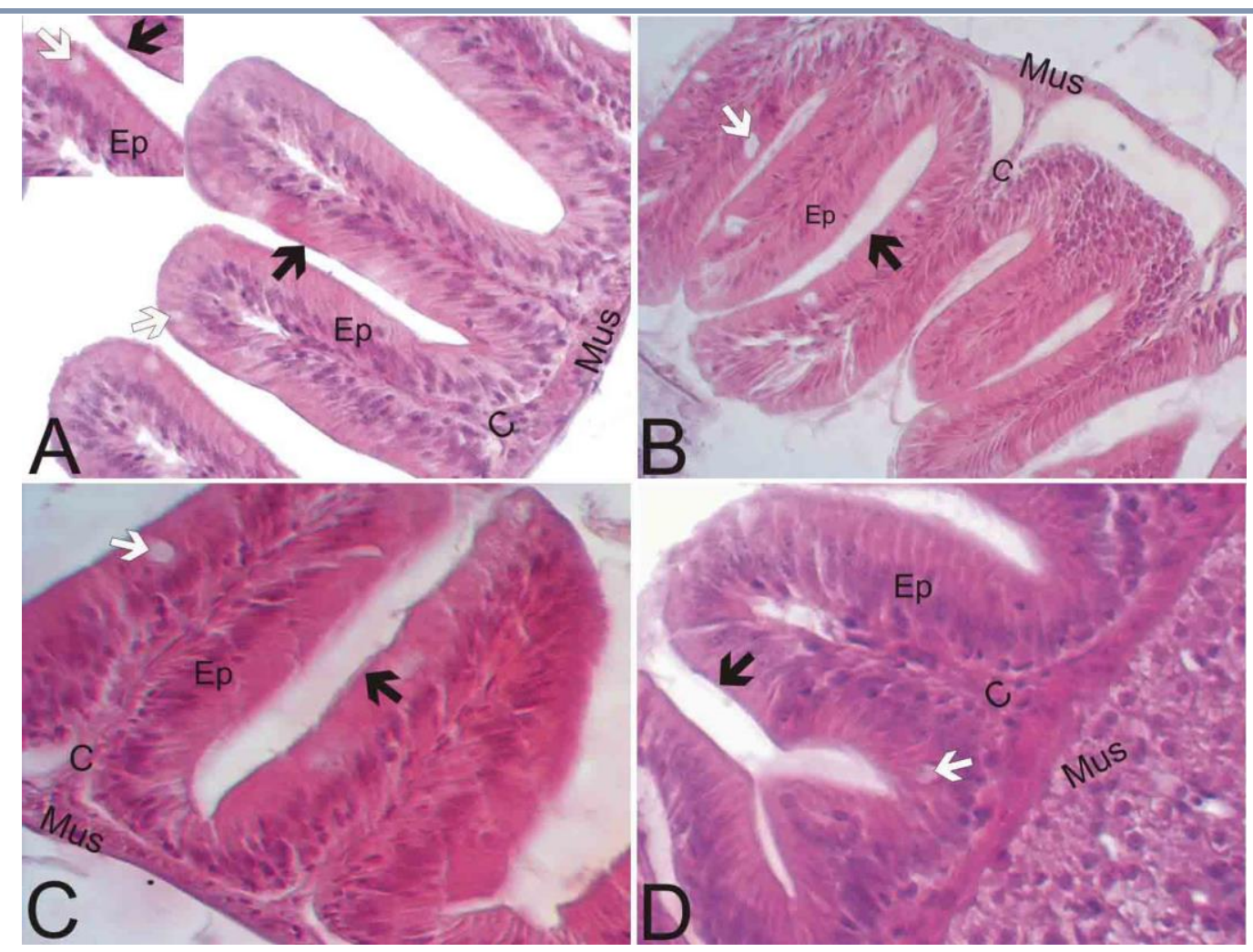

FIGURA 1- Secções histológicas de intestino de Danio rerio coradas com HE. A, B, C e D = grupo controle, grupo tratado com 6,8 e $10 \mathrm{ppm}$, respectivamente. $\mathrm{Ep}=$ Tecido epitelial de revestimento simples prismático; $\mathrm{C}=$ Tecido conjuntivo frouxo da submucosa intestinal; Mus = Tecido muscular liso; Seta preta = Borda estriada; Seta branca $=$ células caliciformes. Aumento de 400x. Incarte com detalhe das células absortivas intestinais e caliciformes.

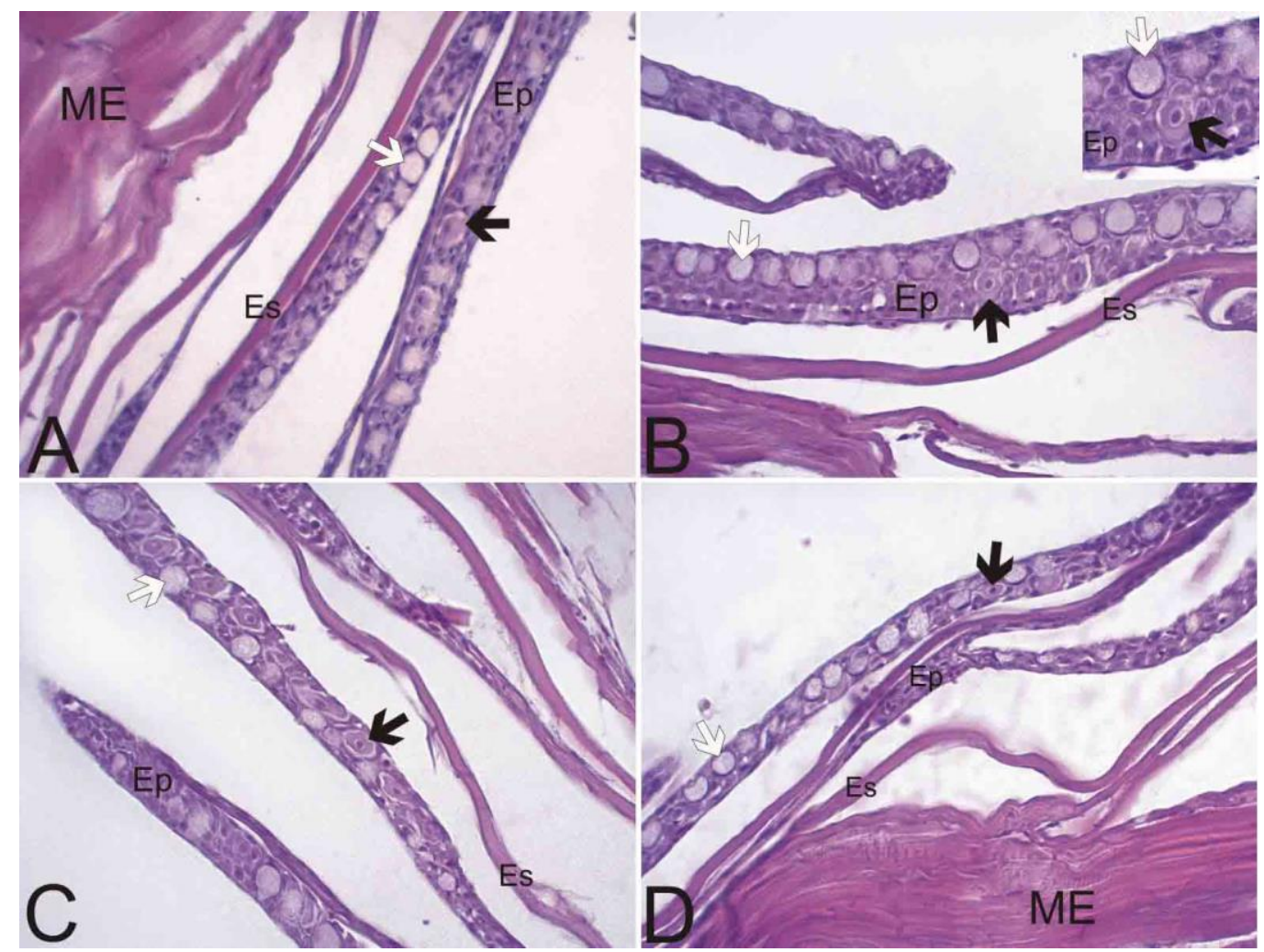

FIGURA 2- Secções histológicas do epitélio da pele de D. rerio coradas com HE. A: Grupo Controle; B: 6 ppm; C: 8 ppm; D: $10 \mathrm{ppm}$. Seta preta = células de Club; Seta branca = células mucosas. Ampliação de 400x. Incarte detalhando células Club e caliciformes. 


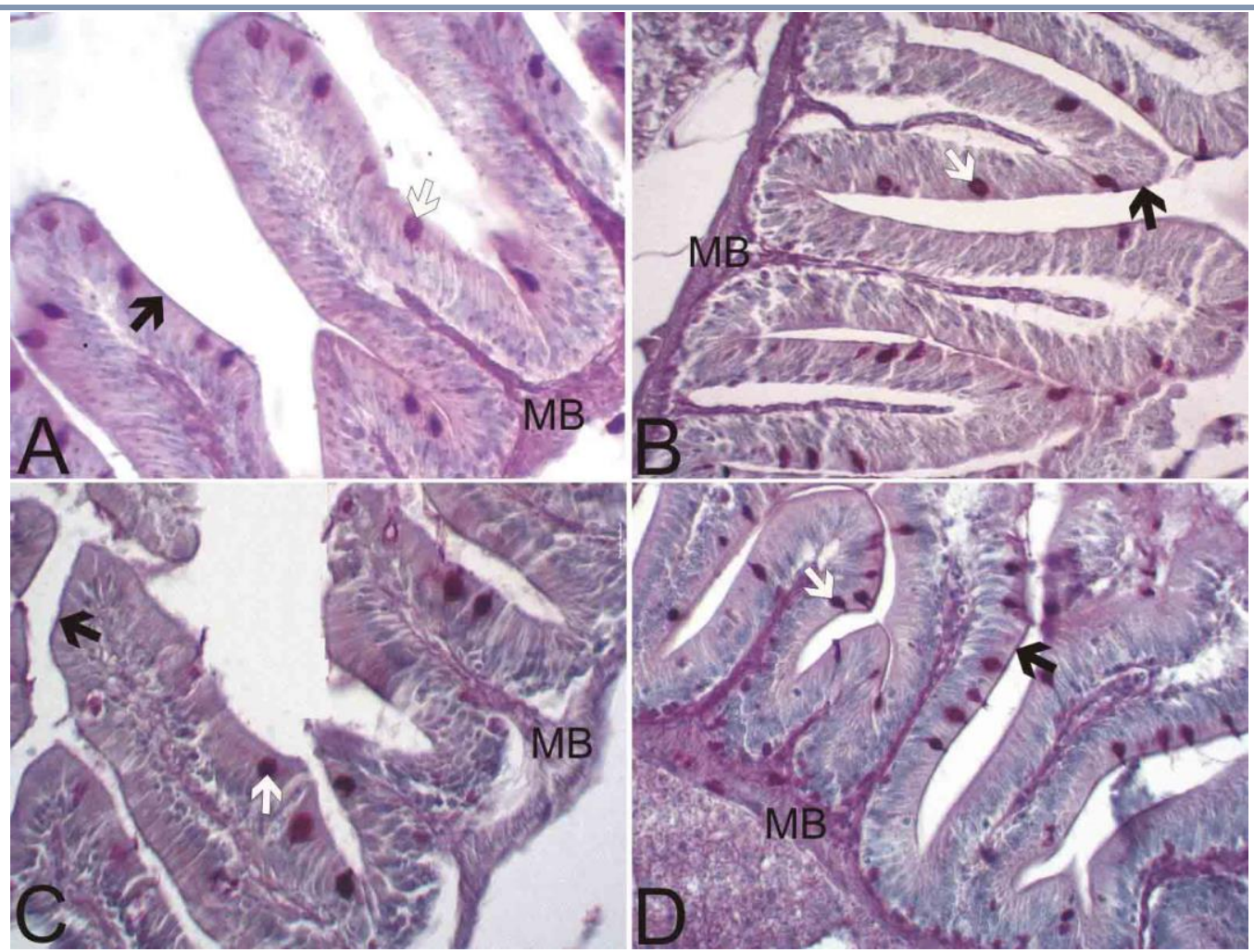

FIGURA 3- Secções histológicas de intestino de Danio rerio coradas com PAS. A, B, C e D = grupo controle, grupo tratado com 6, 8 e 10 ppm, respectivamente. $\mathrm{MB}=$ Membrana Basal; Seta preta = Borda estriada; Seta branca = células caliciformes. Aumento de 400x

No epitélio da pele, as células mucosas e a membrana basal foram PAS positivas em todos os grupos de estudo (Figura 4). As propriedades lubrificantes do muco produzido pelas células

mucosas da pele de peixes proporcionam uma maior proteção contra agente externo, desde partículas inorgânicas até organismos biológicos ${ }^{16}$.

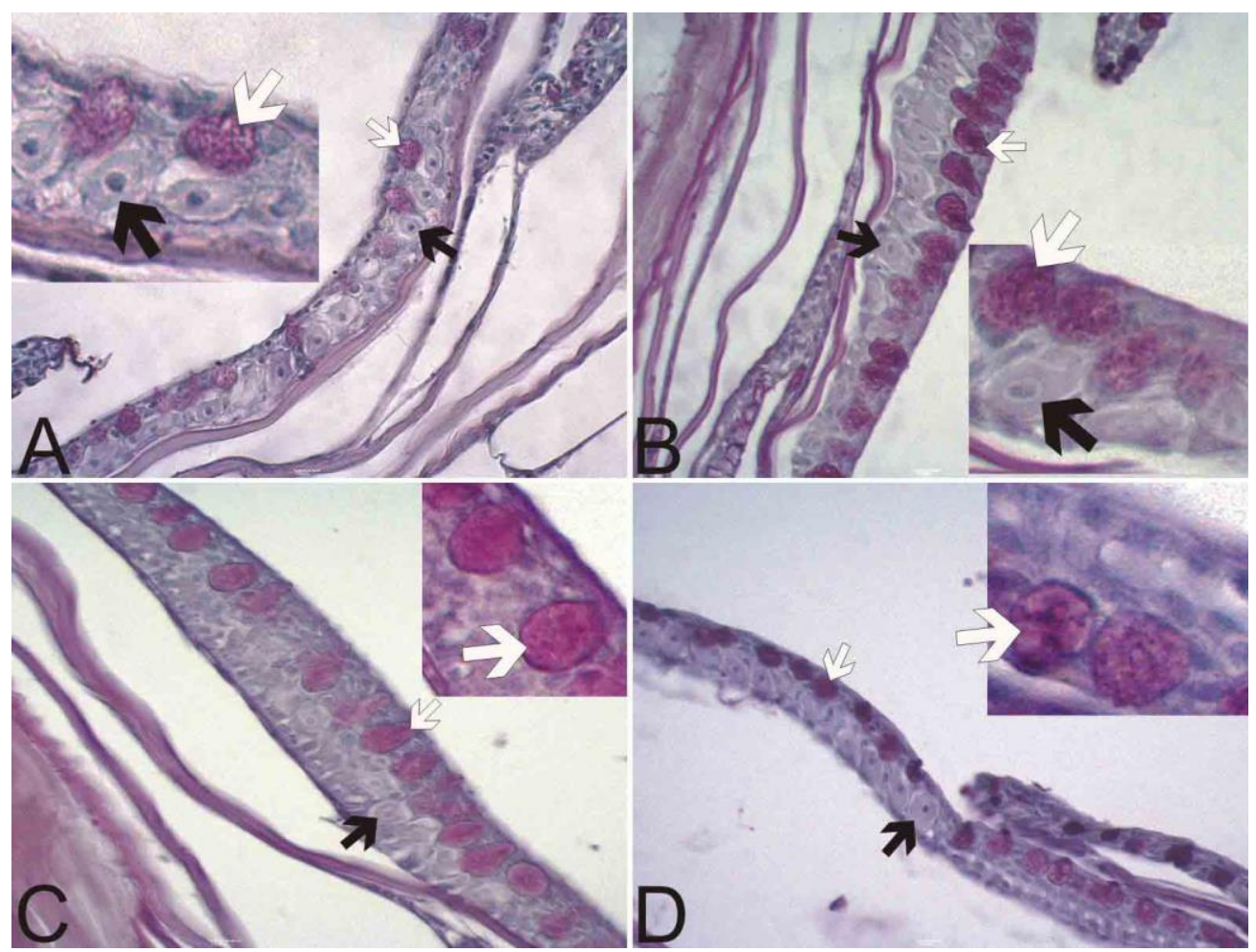

FIGURA 4- Secções histológicas do epitélio da pele de D. rerio coradas com PAS. A: Grupo Controle; B: 6 ppm; C: 8 ppm; D: 10ppm. Seta preta = células de Club; Seta branca = células mucosas. Ampliação de 400x. Incartes mostrando detalhe das células calciformes 
Imunohistoquímica

O antígeno de proliferação celular foi observado na base das vilosidades intestinais em todos os grupos estudados. A marcação foi nuclear nas células epiteliais presentes ao revestimento intestinal (Figura 5). A base das vilosidades intestinais forma criptas onde há intensa atividade mitótica para renovação do epitélio de revestimento e glandular ${ }^{19}$. Devido à PCNA ser uma proteína que atua na regulação do ciclo celular $^{20,21}$, sua imunomarcação pode indicar duas situações diferentes na célula, uma onde estão ocorrendo reparos nas cadeias de DNA, e outra em preparação para divisão celular.

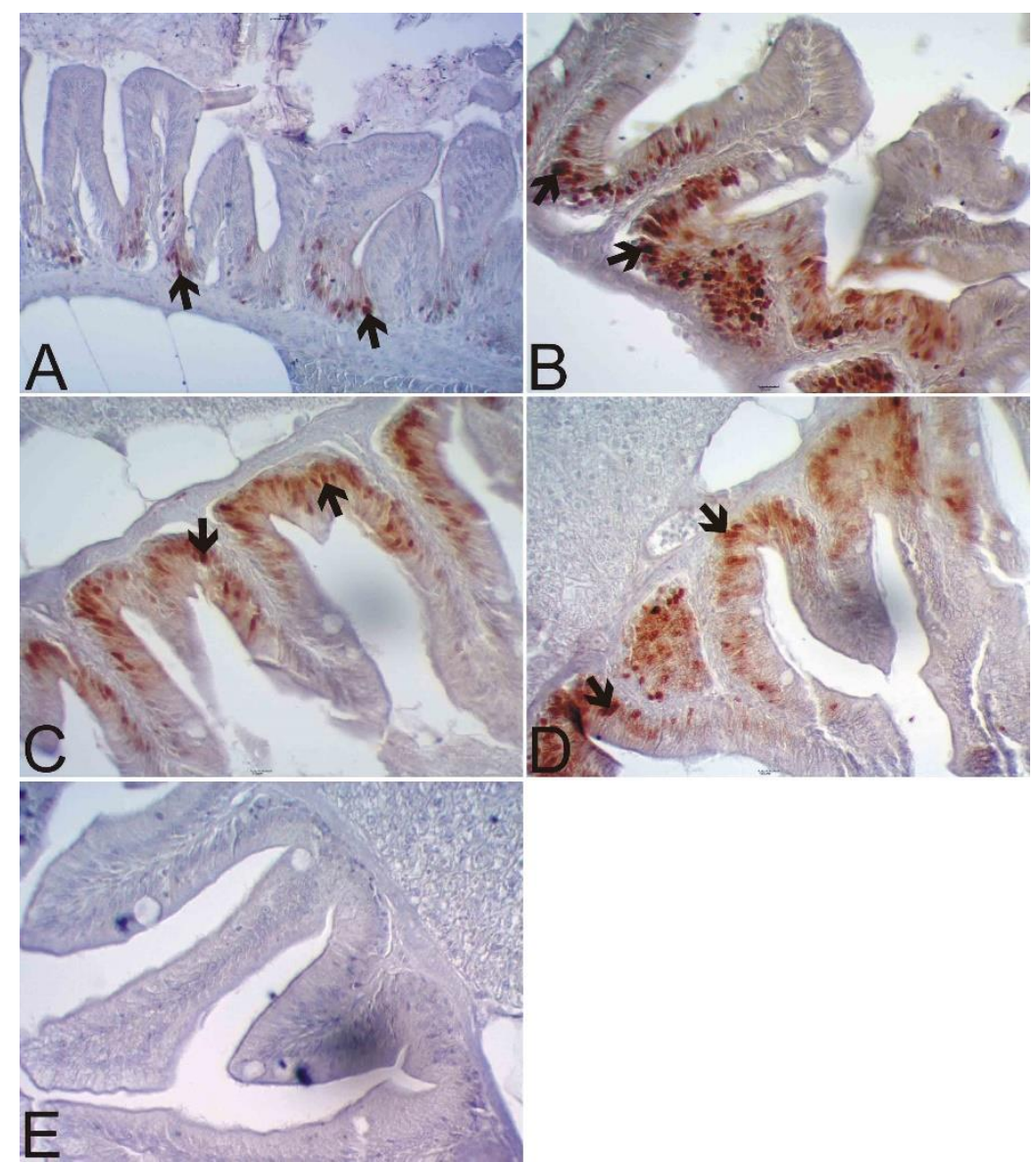

FIGURA 5- Imunohistoquímica por PCNA em intestino de D. rerio. A, B, C e D = grupo controle, grupo tratado com 6 , 8 e 10 ppm, respectivamente, $E=$ controle negativo da técnica. Seta preta = células PCNA positivas. Aumento de 400x.

\section{Morfometria}

A altura das vilosidades intestinais foi maior nos grupos tratados com 6 e 8 ppm do corante PR5 em relação ao grupo controle (Figura 6; p<0,05). Entretanto, a altura dos enterócitos não mostrou diferença entre esses grupos. $\mathrm{O}$ aumento observado nas vilosidades intestinais pode ter sido em decorrência do aumento da camada submucosa, uma vez que essa se constitui de tecido conjuntivo frouxo, com vasos sanguíneos e nervos ${ }^{22}$. Na concentração de 10 ppm observou-se uma resposta diferente ao estímulo causado pelo corante. Nesse caso, houve diminuição da altura da vilosidade no entanto sem diferença estatística em relação ao controle, resultado similar ao encontrado em estudo com o pesticida Temefós também em $D$. rerio $^{23}$. Não houve diferença estatística da espessura das vilosidades intestinais, altura dos enterócitos e tamanho da borda estriada entre os grupos $(\mathrm{p}>0,05)$.
O número de células PCNA positivas foi maior nos grupos tratados com corante PR5 em relação ao controle (Figura 7; p<0,05). Desse modo, a marcação positiva aumentada nos tratados sugere que está havendo uma maior renovação do epitélio, bem como reparo no DNA dos enterócitos, devido à agressão causada pelo corante. Não houve diferença estatística entre os tratados, no entanto foi observado um número maior de células marcadas no grupo 8 ppm em relação ao grupo $10 \mathrm{ppm}$. Esse resultado pode ser relacionado à menor altura das vilosidades observado com 10 ppm.

O número de células mucosas do epitélio intestinal foi maior nos grupos tratados em relação ao controle (Figura $8 ; \mathrm{p}<0,05$ ). Esse aumento de células mucosas pode estar relacionado a uma tentativa do organismo do animal a aumentar a proteção da estrutura intestinal contra a agressão causada pelo corante PR5. Esse comportamento decorre do fato de que uma 
quantidade maior de células significará em uma quantidade maior de muco produzido, incrementando a formação de um revestimento protetor, que separa os tecidos das atividades enzimáticas em seu lúmen e como um lubrificante auxiliando a passagem de alimentos através do intestino, e evitando danos mecânicos e químicos no epitélio intestinal ${ }^{24}$.

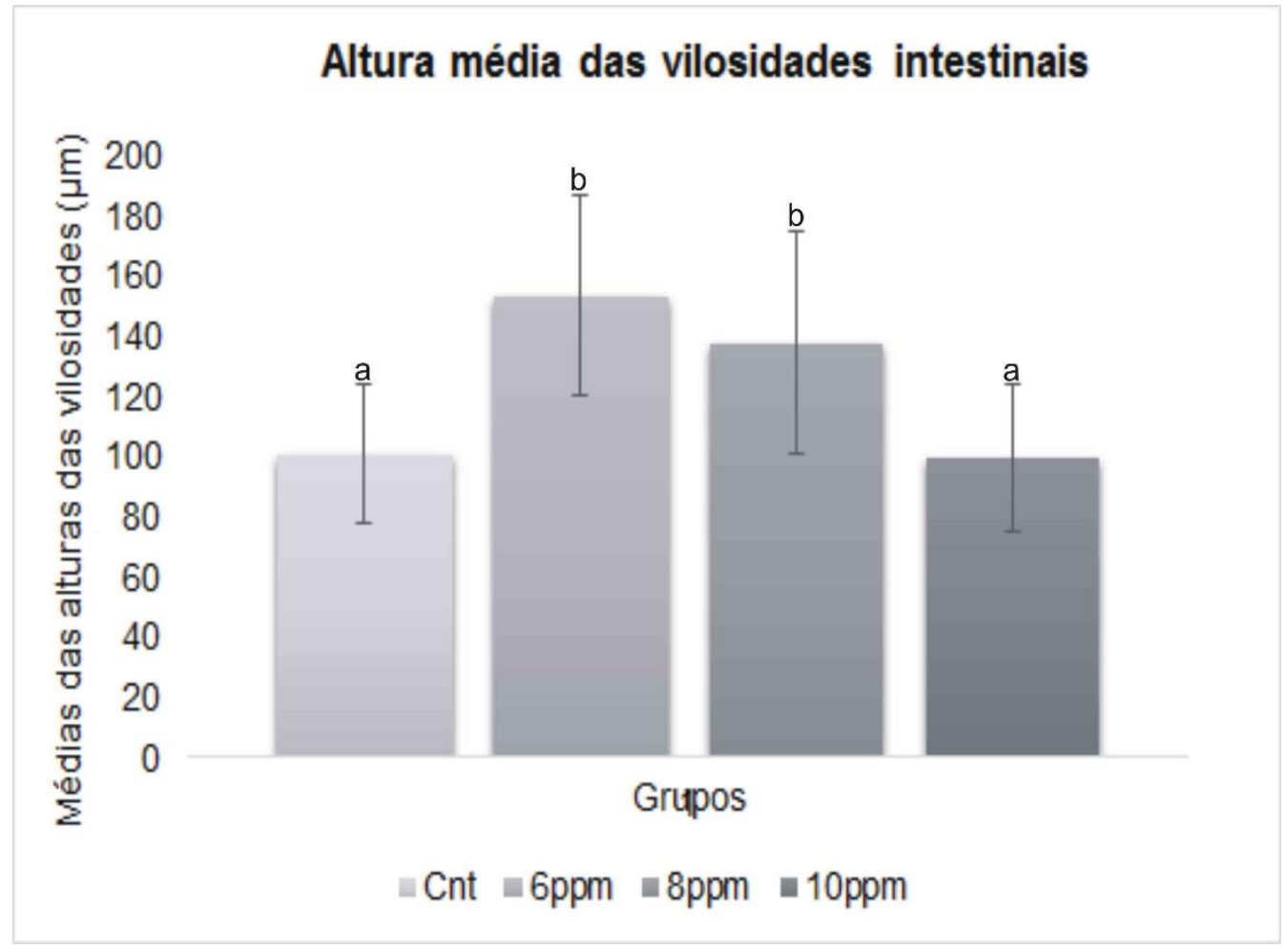

FIGURA 6- Altura média das vilosidades do intestino de D. rerio. Grupo controle = cnt; Grupos tratados com 6 ppm, 8 ppm e 10 ppm. Diferença estatística significativa entre a e b.

\section{Contagem das células PCNA positivas}
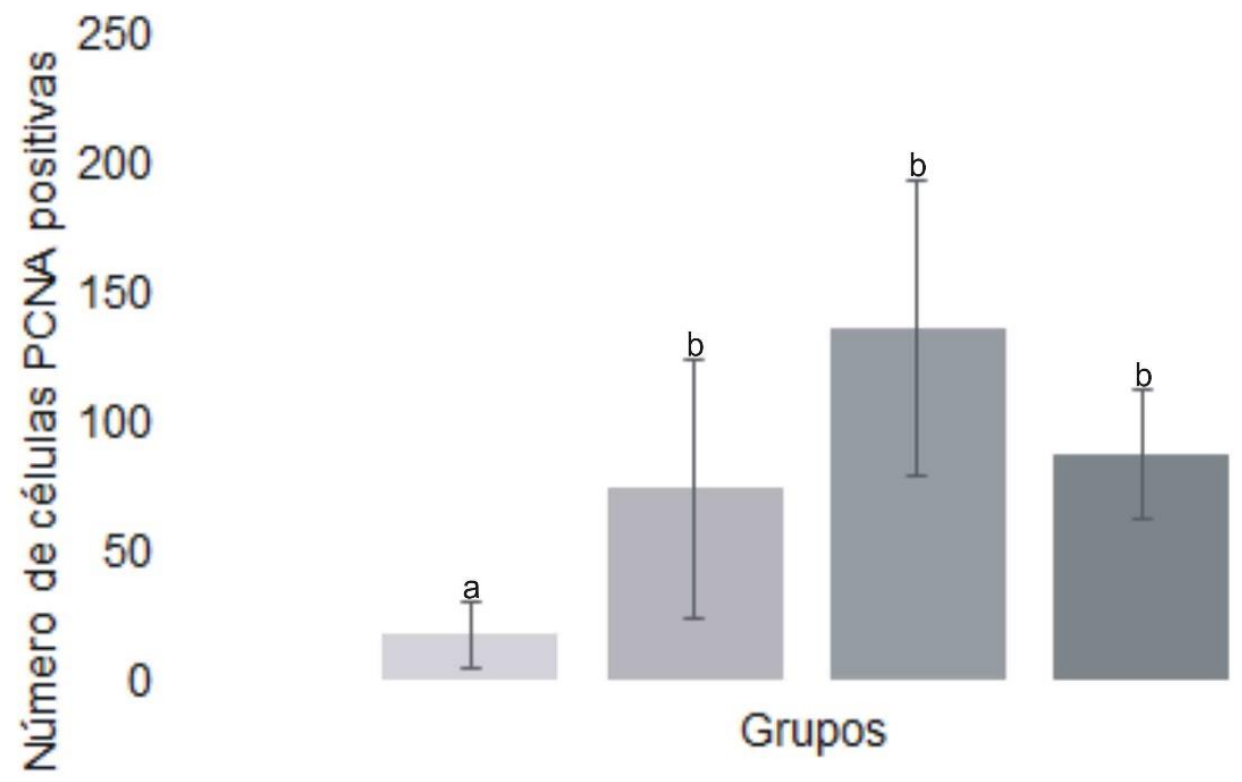

Cnt $\backsim 6 \mathrm{ppm}=8 \mathrm{ppm}=10 \mathrm{ppm}$

FIGURA 7- Número de células PCNA positivas em intestino de D. rerio. Grupo controle = cnt; Grupos tratados com 6 ppm, 8 ppm e 10 ppm. Diferença estatística significativa entre a e b. 


\section{Células Mucosas do Intestino}
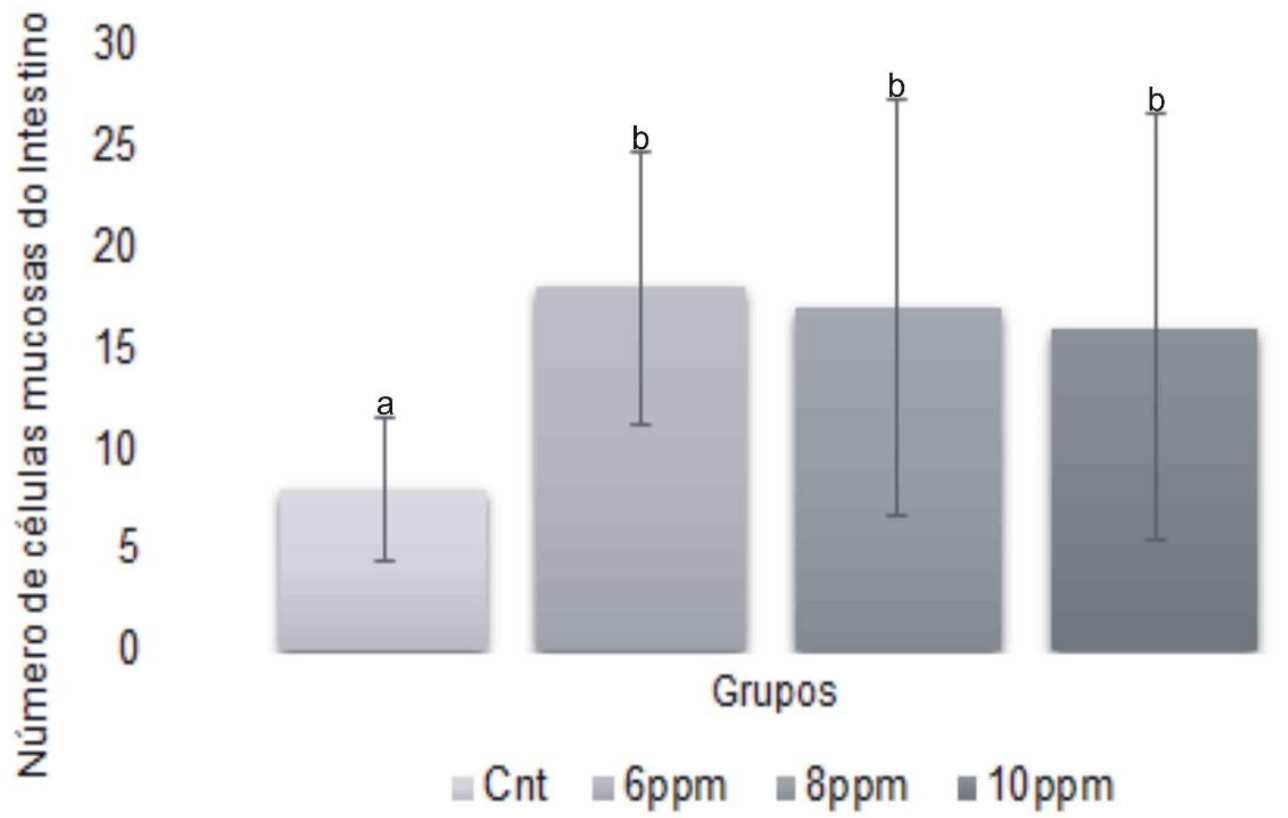

FIGURA 8- Número de células mucosas em epitélio de Intestino de D. rerio. Grupo controle e Grupos tratados com 6 ppm, 8 ppm e 10 ppm. Diferença estatística significativa entre a e b.

\section{Espessura média da pele}
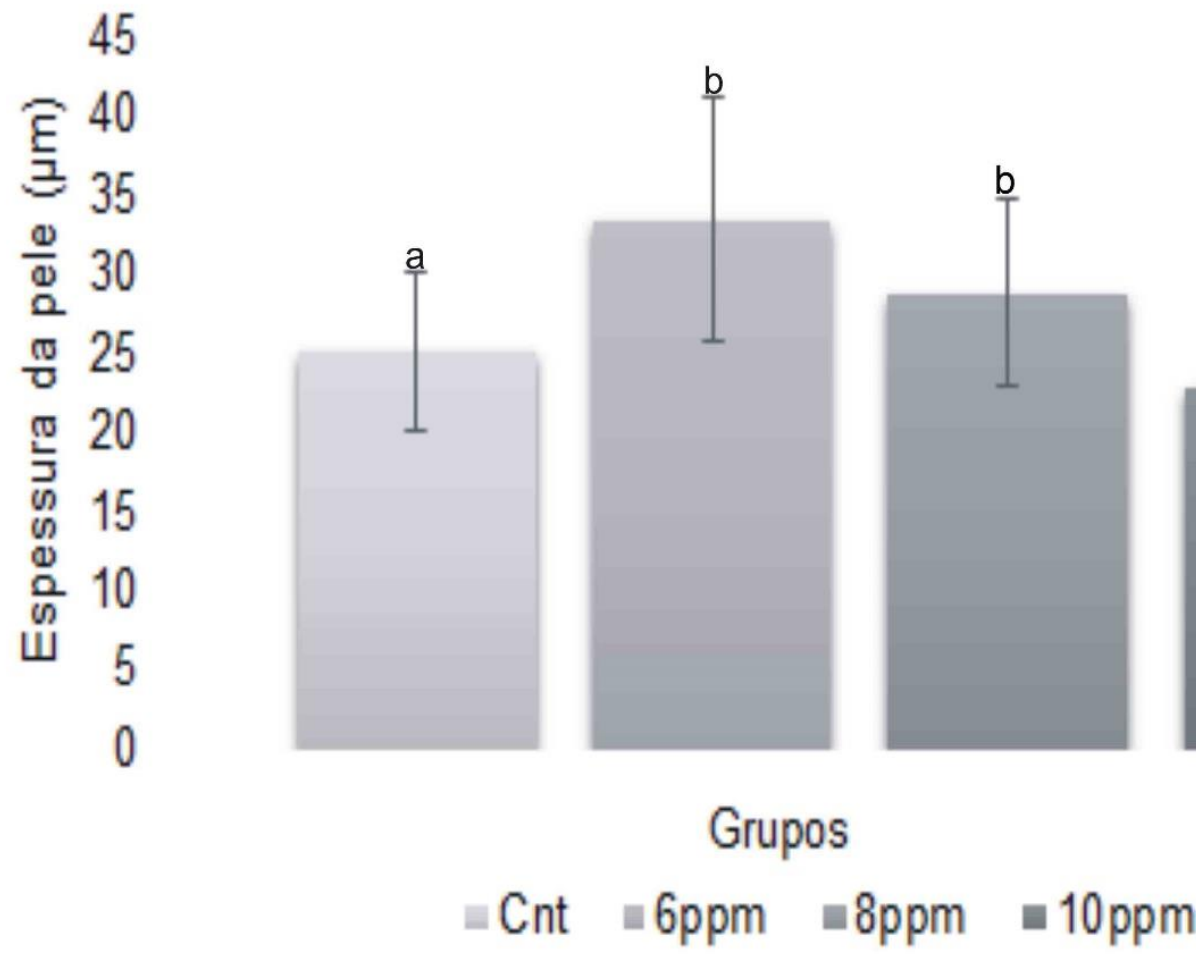

FIGURA 9- Espessura média de epitélio de pele de D. rerio. Grupo controle = cnt; Grupos tratados com 6 ppm, 8 ppm e 10 ppm. Diferença estatística significativa entre a e b. 


\section{Células mucosas da pele}
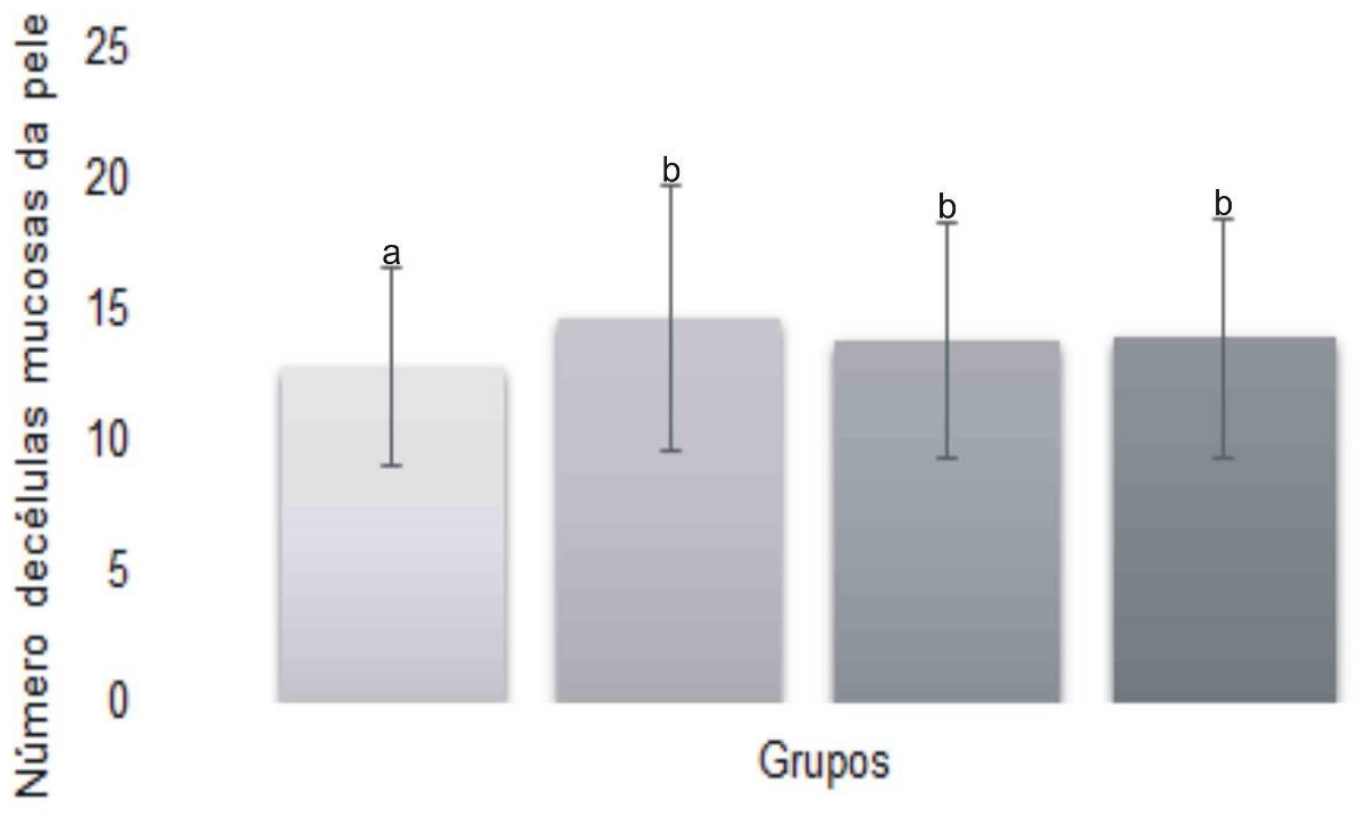

Controle $=6 \mathrm{ppm}=8 \mathrm{ppm}=10 \mathrm{ppm}$

FIGURA 10- Número de células mucosas em epitélio de pele de D. rerio. Grupo controle e Grupos tratados com 6 ppm, 8 ppm e 10 ppm. Diferença estatística significativa entre a e b.

O presente experimento mostrou aumento da espessura do epitélio da pele quando exposto 6 e 8 ppm testada (Figura 9; p<0,05). Em geral, para aumentar a linha de defesa contra a entrada do tóxico no organismo, observa-se aumento na espessura do tecido, mediante o recrutamento de células, hiperplasia ou até hipertrofia celular ${ }^{25}$. Como em outros parâmetros estudados aqui, o grupo $10 \mathrm{ppm}$ apresentou um resultado inverso ao esperado, e ficou registrada uma redução na espessura epitélio. É possível que nesse caso tenha ocorrido uma estimulação para atrofia das células. Os animais dos grupos tratados também tiveram alterações no número de células mucosas da pele, registrando-se aumento nos grupos tratados em relação ao controle (Figura 10; $\mathrm{p}<0,05)$. As alterações na densidade dessas células podem refletir em alterações na quantidade de muco produzida pelo epitélio, que constitui primeira linha de defesa dos peixes contra contaminantes. Esses resultados são esperados e estão em conformidade com a literatura, uma vez que sob condições de estresse ambiental, o aumento de atividade secretora das células mucosas e suas relações com processos imunes constituem indicadores de contaminação ${ }^{24,26}$.

\section{Conclusão}

Por meio do presente estudo, foi possível verificar a subletalidade das concentrações de 6,8 e 10 ppm do corante PR5, comumente descartado nos corpos d'água como rejeito da indústria têxtil. Conclui-se que, durante o período de estudo, tais concentrações do corante PR5 não são capazes de alterar a arquitetura morfológica dos tecidos, nem de induzir necrose, apoptose, formação de edema e perda de aderência celular. Por outro lado, alterações importantes foram observadas na pele e no intestino, como aumento das vilosidades intestinais, de células em proliferação e células caliciformes. Essas alterações podem levar, em médio ou longo prazo, a modificações no funcionamento desses órgãos e a impactos futuros importantes na capacidade de os peixes se alimentarem eficazmente ou na capacidade de a pele exercer sua função correta.

\section{Declaração de conflitos de interesses}

Os autores do artigo afirmam que não houve nenhuma situação de conflito de interesse, tais como propostas de financiamento, emissão de pareceres, promoções ou participação em comitês consultivos ou diretivos, entre outras, que pudessem influenciar no desenvolvimento do trabalho.

\section{Agradecimentos}

Agradecemos a UFSJ pela estrutura fornecida, a FAPEMIG e ao CNPq pelo auxílio financeiro. 


\section{Referências}

1- FERNANDES, L.M.; DAVID, S.; LOZIANE, R.D; LOPES, E.A. O perfil socioeconômico dos municípios que compõem a microrregião de Divinópolis -Minas Gerais. Revista da FACED (Impresso), Vol.3, p. 52-60, 2005.

2 - PAGGA, U.; BROWN, D. The degradation of dyestuffs: Part II Behaviour of dyestuffs in aerobic biodegradation tests. Chemosphere. Vol.15, n.4, p. 479 - 491, 1986

3 - CARNEIRO, P. A.; UMBUZEIRO, G. A.; OLIVEIRA, D. P.; ZANONI, M. V. B. Contaminação da água causada por uma matéria têxtil mutagênico effluentes / dyehouse efluentes tendo corantes dispersos. J. Hazard. Mater. v. 174, p. 694 - 699, 2010.

4 - KAUR, S.; KAUR, A. Variability in antioxidant/detoxification enzymes of Labeo rohita exposed to an azo dye, acid black (AB). Comparative Biochemistry and Physiology Part C Toxicology \& Pharmacology, v. 167, p.108 - 116, 2015.

5 - LUCAS, S. M. S.; AMARAL, C.; SAMPAIO, A.; PERES, J. A.; DIAS, A. A. Biodegradation of the diazo dye Reactive Black 5 by a wild isolate of Candida oleophila. Science Direct. Enzyme and Microbial Technology v.39, p. 51 - 55, 2006.

5 - PARK, H.; CHOI, W. Visible light and Fe (III)mediated degradation of Acid Orange 7 in the absence of $\mathrm{H} 2 \mathrm{O} 2$. Journal of Photochemistry and Photobiology A: Chemistry, v. 159, n.3, p. 241-247, 2003.

6 - BARBAZUK, W.B.; KORF, I.; KADAVI, C.; HEYEN, J.; TATE, S.; WUN, E.; BEDELL, J.A.; MCPHERSON, J.D.; JOHNSON, S.L. The syntenic relationship of the zebrafish and human genomes. Genome research, v. 10, n. 9, p. 1351-1358, 2000.

7- VON SPERLING, Marcos. Introdução à qualidade das águas e ao tratamento de esgotos. Editora UFMG, v. 1 pp 460, 1996.

8 - DETRICH, W.H.; WESTERFIELD, M.; ZON, L. The zebrafish, genetics and genomics, CA: Academic Press. v. 60,1999

9 - MARIJIC, V. F.; RASPOR, B. Age- and tissuedependent metallothionein and cytosolic metal distribuition in a native Mediterranean fish Mullus barbatus, from the Eastern Adriatic Sea. Comparative and Biochemistry Physiologic. Part C. v. 143, p. 382387, 2006.

10 - LYNG, F. M.; LYONS A., M.; OLWELL, P.; NÍ SHUILLEABHÁIN, S.; SEYMOUR, C.; COTTEL, D. C.; MOTHERSILL, C. Ionizing radiation induces a stress response in primary cultures of rainbow trout skin. Radiation Research, v. 162, n 2, p. 226 - 232, 2004

11 - MITTAL, A. K.; WHITEAR, M. Keratinization of fish skin with special reference to the catfish Bagarius bagarius. Cell and tissue research, v. 202, n. 2, p. 213230, 1979.

12 - MENKE, A. L., SPITSBERGEN, J. M., WOLTERBEEK, A. P., WOUTERSEN, R. A. Normal anatomy and histology of the adult zebrafish. Toxicologic pathology, v. 39, n.5, p. 759 - 775, 2011.

13 - WANG, Z.; DU, J.; LAM, S. H.; MATHAVAM, S.; MATSUDAIRA, P.; ZHIYUAM G. Morphological and molecular evidence for functional organization along the rostrocaudal axis of the adult zebrafish intestine. BMC Genomics, v. 11, n.2, p. 392-406, 2010

14 - JUNQUEIRA, L. C. U.; CARNEIRO, J. Histologia básica. Rio de Janeiro: Guanabara Koogan, 2008.

15- CAMINHA, E. S.; BRUCH, G. E.; ROMANO, L. A.; BARROS, D. M. Análise histopatológica de órgãos de zebrafish expostos a nanotubos de carbono funcionalizados com polietilenoglicol. In: XII MOSTRA DA PRODUÇÃO UNIVERSITÁRIA, 2013, Rio Grande. Resumos...Rio Grande: Universidade Federal do Rio Grande, 2013.

16 - ELLIS, A. E. Innate host defense mechanisms of fish against viruses and bacteria. Developmental \& Comparative Immunology, v. 25, n. 8-9, p. 827-839, 2001 .

17 - SHEPHARD, Kerry L. Functions for fish mucus. Reviews in fish biology and fisheries, v. 4, n. 4, p. 401-429, 1994.

18 - MARCHETTI, L.; CAPACCHIETTI, M.; SABIETTI, M. G.; ACCILI, D.; MATERAZZI, G.; MENGHI, G. Histology and carbohydrate histochemistry of the alimentary canal in the rainbow trout Oncorhynchus mykiss. Journal of Fish Biology v. 68, p. $1808-1821,2006$.

19 - COELLO, W. F.; KHAN, A. Q. Protection against heavy metal toxicity by mucus and scales in fish. Archives of environmental contamination and toxicology, v. 30, p. 319-326, 1996.

20 - BRAVO, Rodrigo et al. Cyclin/PCNA is the auxiliary protein of DNA polymerase- $\delta$. Nature, v. 326, n. 6112 , p. $515,1987$.

21 - THOMÉ, R. G. et al. Apoptosis, cell proliferation and vitellogenesis during the folliculogenesis and follicular growth in teleost fish. Tissue and Cell, v. 44, n. 1, p. 54-62, 2012.

22 - LILIAN, C. M. Estrutura, ultraestrutura e histoquímica do aparelho digestório do Prochilodus lineatus. Análise da diversidade da microbiota intestinal de Prochilodus lineatus e Pterygoplichthys anisitsi. Tese de Doutorado, Universidade Estadual Paulista, Jaboticabal, São Paulo, 2010. 21 - TIBBETTS, I.R. The distribution and function of mucous cells and their secretions in the alimentary tract of Arrhamphus sclerolepis krefftii. Journal of Fish Biology, v. 50, p. 809-820, 1997.

23 - SANTOS, H.B.; VIEIRA, L.; ALVES, S. N.; THOMÉ, R. Análise do intestino delgado de Danio rerio exposto a organofosforado e detergente: um estudo histológico e morfométrico. Revista Conexão Ciência, v. 11, n. 2, p. 51-58, 2016.

24 - RODRIGUES, Gabriela Zimmermann Prado et al. Evaluation of intestinal histological damage in zebrafish exposed to environ-mentally relevant concentrations of manganese. Ciência e Natura, v. 40, p. e52, 2018.

25 - SALES, Camila Ferreira et al. Proliferation, survival and cell death in fish gills remodeling: From injury to recovery. Fish \& shellfish immunology, v. 68, p. 10-18, 2017.

26 - PRETTI, Carlo et al. Acute toxicity of ionic liquids to the zebrafish (Danio rerio). Green Chemistry, v. $8, \mathrm{n}$. 3, p. 238-240, 2006. 